ENVIRONMENTAL RESTORATION PROGRAM

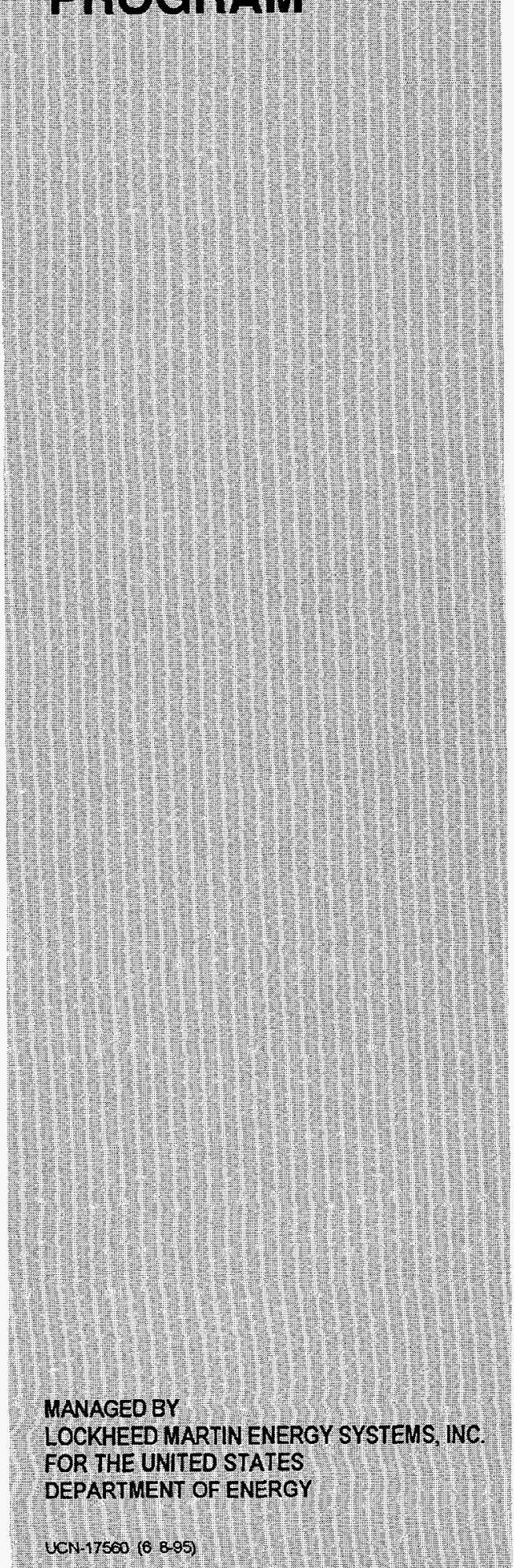

\section{Work Plan for Mercury Treatability} Study in Upper East Fork Poplar Creek at DOE's Y-12 Site in Support of the Reduction of Mercury in Plant Effluent Program (RMPE)

\section{RECEIVED \\ MAR 041998 \\ OS:TI}

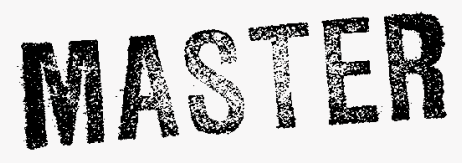

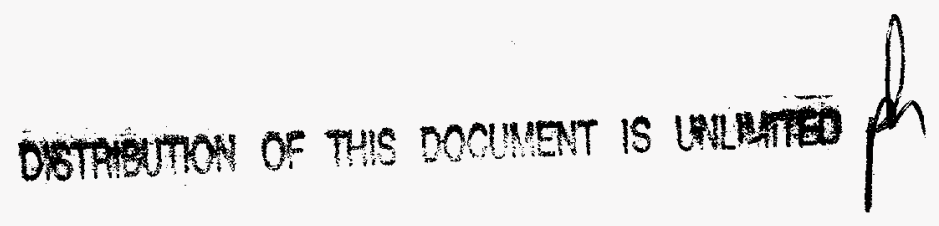

This document has been approved by the Y-12 Technical Information Office for release to the public. Date: $02 / 17 / 98$ 


\section{TN \& Associates}

contributed to the preparation of this document and should not be considered and eligible contractor for its review. 


\section{DISCLAIMER}

This report was prepared as an account of work sponsored by an agency of the United States Government. Neither the United States Government nor any agency thereof, nor any of their employees, makes any warranty, express or implied, or assumes any legal liability or responsibility for the accuracy, completeness, or usefulness of any information, apparatus, product, or process disclosed, or represents that its use would not infringe privately owned rights. Reference herein to any specific commercial product, process, or service by trade name, trademark, manufacturer, or otherwise does not necessarily constitute or imply its endorsement, recommendation, or favoring by the United States Government or any agency thereof. The views and opinions of authors expressed herein do not necessarily state or reflect those of the United States Government or any agency thereof. 


\section{DISCLAIMER}

Portions of this document may be illegible electronic image products. Images are produced from the best available original document. 


\title{
Work Plan for Mercury Treatability Study in Upper East Fork Poplar Creek at DOE's Y-12 Site in Support of the Reduction of Mercury in Plant Effluent Program (RMPE)
}

Date Issued-February 1998

\author{
Prepared by \\ TN \& Associates \\ Oak Ridge, Tennessee \\ under subcontract 73K-GWU11C \\ Prepared for the \\ U.S. Department of Energy \\ Office of Environmental Management \\ under budget and reporting code EW 20 \\ Environmental Management Activities at the \\ OAK RIDGE Y-12 PLANT \\ Oak Ridge, Tennessee 37831 \\ managed by \\ LOCKHEED MARTIN ENERGY SYSTEMS, INC. \\ for the \\ U.S. DEPARTMENT OF ENERGY \\ under contract DE-AC05-84OR21400
}




\title{
APPROVALS
}

\author{
WORK PLAN \\ for \\ MERCURY TREATABILITY STUDY \\ IN UPPER EAST FORK POPLAR CREEK AT DOE'S Y-12 SITE \\ IN SUPPORT OF THE \\ REDUCTION OF MERCURY IN PLANT EFFLUENT PROGRAM \\ (RMPE) \\ Oak Ridge, Tennessee
}

$\frac{1 C 21087-16-98}{\text { Lockheed Martin } \text { Energy Systems EMEF }}$

RMPE Field Specialist (Richard Woods)

Lockheed Martin Energy Systems

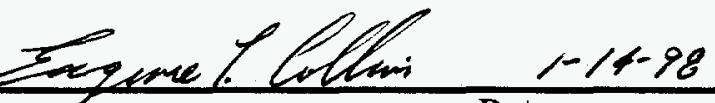

Y-12 Site Environmental Compliance (E. Thomas Collins)

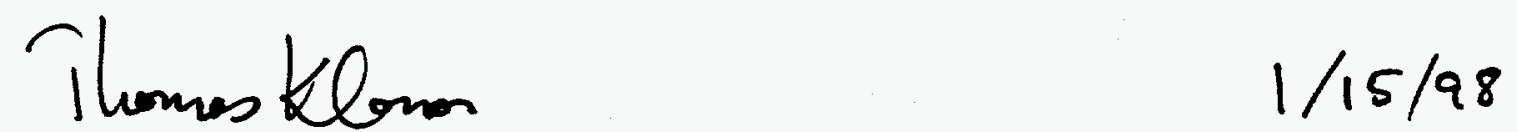

Lockheed Martin Energy Research LMER

Date

Field Support Team Leader (Thomas Klasson)

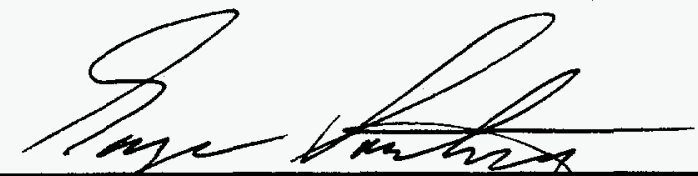

Lockheed Martin Energy Research LMER

$1 / 15 / 98$

RMPE Program Scientist (George Southworth)

Date

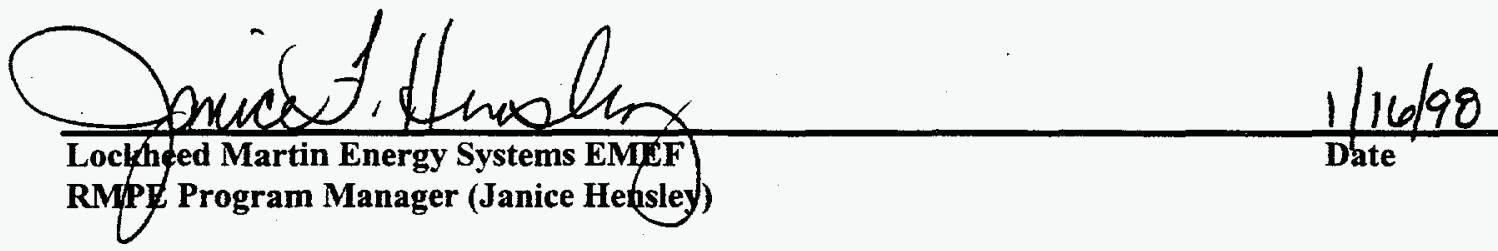




\section{CONTENTS}

Approvals i

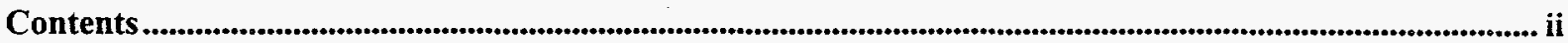

1.0 BACKGROUND

2.0 ROLES AND RESPONSIBILITIES

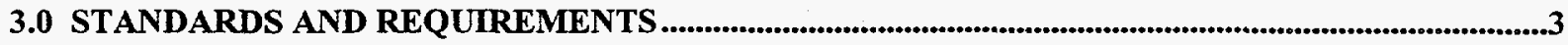

4.0 EQUIPMENT

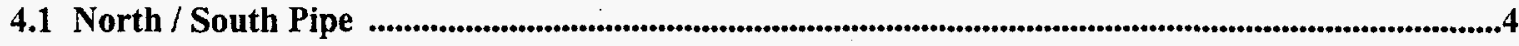

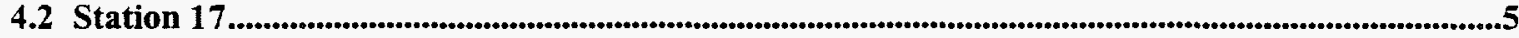

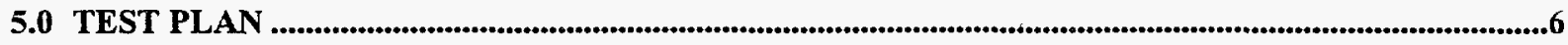

6.0 SAMPLING REQUIREMENTS

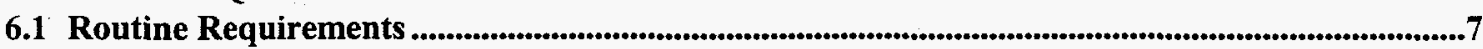

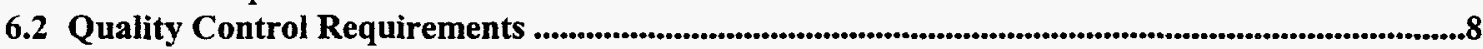

7.0 HEALTH AND SAFETY REQUIREMENTS ............................................................................................9

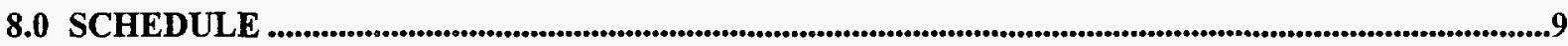

9.0 EQUIPMENT DECONTAMINATION AND DISMANTLEMENT .....................................................9

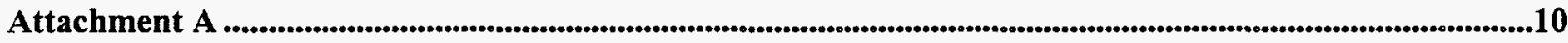




\subsection{BACKGROUND}

Over the past ten years the Department of Energy Y-12 Site's Reduction of Mercury in Plant Effluents (RMPE) project has carried out an aggressive investigative program of identifying sources of mercury which are influencing the levels of mercury in Upper East Fork Poplar Creek (UEFPC) and exiting the site at Station 17. The driver for these activities has been and continues to be the site's National Pollution Discharge Elimination Permit (NPDES). This permit establishes certain remedial actions, the schedule for these actions and requires that the mercury in the creek be equal to or less than 5 grams per day by December 31, 1998 and the concentration in the creek be equal to or less than $.012 \mu$ grams per liter on the last day of the permit, April 27, 2000.

Based on the results of the investigative work, the sources of mercury exceeding criteria levels have been remediated. Key remediation activities were:

- the removal of mercury contaminated piping

- the rerouting of clear water around mercury contaminated piping

- the cleaning and relining of mercury contaminated piping

- the cleaning of mercury containing sludges and sediments from sumps, tanks and basins

- the design and installation of treatment systems for point sources of mercury entering the creek.

By the end of fiscal year 1997, with the exception of Outfall 163, remedial actions will be either underway or complete for all known sources of mercury contributing $1 \mathrm{gram}$ per day or more to UEFPC. Outfall 163 is a high flow, low concentration source of $1-2$ grams of mercury per day. Based on the current levels of mercury in the creek and the creek's response to previously completed remedial actions, it is unlikely that the 5 gram per day limit will be reached by the prescribed date nor will the more difficult requirement of $.012 \mu$ gram per liter be reached. Thus, as the site begins negotiation of the next permit with the Tennessee Department of Environment and Conservation (TDEC), knowledge will be needed as to the "best available technology" that is available for the Department of Energy (DOE) to employ in its final efforts to reach permit levels. The Mercury Treatability Study, outlined in the following paragraphs, has the purpose of providing the DOE with the information to allow knowledgeable decision making and effective negotiation with the state regulatory personnel.

Two sites are to be evaluated for the implementation of future Mercury Treatability Systems, the discharge at the North/South Pipe (Outfall 200) and the inlet to Lake Reality. The Lake Reality inlet was chosen since it is representative of the future Station 17 waters following the planned bypass of Lake Reality. The North/South pipe discharge is the TDEC recognized "head waters" of the creek. The mercury contamination at this point in the creek is predominately dissolved mercury. By the 
time the creek reaches Station 17, the dissolved mercury has become attached to sediment and as a result, the treatment system requirements must be different at the two sites.

The objectives for the work at North/South Pipe will be to conduct a short term series of tests to establish the sorbent treatment systems which have the greatest capacity for removing mercury. The data collected from these tests will allow differentiation of the treatment system candidates. The objectives of the tests will be to size the treatment system and estimate the equipment costs for a full scale treatment system. Following selection of the most likely resin candidates, longer term tests, as a later phase of work, may be conducted in order to establish the treatment economies via breakthrough studies and resin regeneration studies.

The second objective for the work will be the evaluation of potential treatment/filtration systems for implementation at Station 17 , the point that the creek exits the site. The test will be conducted at the Lake Reality inlet because of the planned bypass of the lake. The range of treatment/filtration systems to be evaluated will be limited to those which could be implemented for treatment of the total creek in dry weather, recognizing the limited space available for installation of facilities at this site.

\subsection{Roles and Responsibilities}

The following outlines the roles and responsibilities of the principal individuals I organizations involved in this treatability study.

\section{TN \& Associates (TN\&A)}

TN\&A will serve as the treatability study coordinator. In this role they will coordinate the work of all project participants, tracking technical progress and reporting both technical progress and costs incurred. TN\&A will manage the contracts of Alabama A\&M University and Frontier Geosciences. ORNL Chemical Technology will support the project and work under a work order provided by Lockheed Martin Energy Systems (LMES). TN\&A will be responsible for developing the Work Plan and the Health and Safety Plan for the project and working to obtain approvals. Joe Johnston will be the lead person from TN\&A.

\section{Alabama A\&M University (AAMU)}

AAMU will serve as the technical support contractor for the project. They will be responsible for providing technical leadership for the evaluation of treatment media candidates, the recommendation of candidates for testing, the planning of the tests in conjunction with the field support contractor, including the establishment of the data quality objectives, the evaluation of the test data and the reporting of the results of the tests. Daryush lla will be the lead researcher from Alabama A\&M University 
Oak Ridge National Laboratory, Chemical Technology Division

The Oak Ridge National Laboratory, Chemical Technology Division (Chem Tech), will serve as the field support contractor. In this role they will provide the equipment and install the equipment in the field. Chem Tech will start up the equipment and provide routine monitoring, taking samples as required. Following completion of tests, Chem Tech will decontaminate and dismantle the equipment and remove from the site. In addition to the duties described, Chem Tech will also provide technical consultation with Alabama A\&M University on the media candidates being evaluated. Thomas Klasson will be the lead person from Chem Tech.

\section{Frontier Geosciences}

Frontier Geosciences will also serve as a technical support contractor and will be responsible for consultation with the project team on $\mathrm{Y}-12$ specific mercury background information and for consulation on the treatment media candidates, the planning of the tests in conjunction with the field support contractor, the evaluation of the test data and the reporting of the results of the tests. Ralph Turner will be the lead person from Frontier Geosciences.

Lockheed Martin Energy Systems (LMES)

LMES is ultimately responsible to the DOE for the treatability study and the overall RMPE project. LMES will hold the contract with TN\&A and will issue work orders for Chem Tech support. Janice Hensley is the Project Manager and Richard Woods is the Field Specialist for LMES.

\subsection{STANDARDS AND REQUIREMENTS}

This work will be conducted at the Y-12 Site and as a result, all of the LMES Y-12 and the EMEF rules and regulations apply. In addition, the TDEC, DOE Oversight Division, will be notified and may elect to have involvement in the work. Approval of this work plan by Y-12 Environmental Compliance and by EMEF-ER representatives will constitute the necessary approvals to conduct the tests and discharge the treated water into Upper East Fork Poplar Creek. The RMPE Program Document Y/ER-115 provides the general program management plan guidance for the activities, Y/ER-221R1 provides general quality guidance and Y/ER- XXX (in the review/approval process at present time) provides general health and safety guidance. Project specific documents generated for this work are this work plan, a project specific health and safety plan and the data quality objectives document to be developed by AAMU. 


\subsection{EQUIPMENT}

\subsection{North / South Pipe Equipment}

The equipment will be installed on the north side of the creek near the outlet of Outfall 200 . The equipment will be rack mounted and temporarily installed. Power ( 110 volt ac) for the pump will be supplied from Building 9417-8. Key features for the equipment will be as follows. A sketch of the equipment is shown in Figure 1.

- Six (6) columns will be installed. The columns will be approximately $2.5 \mathrm{~cm}$. in diameter and $35 \mathrm{~cm}$. in length and constructed of glass and teflon with screens at top and bottom to contain the sorbents. The flow in the column will be top to bottom to prevent levitation of the sorbents. One of the columns will be used for a standard sorbent as a reference and one column will not be filled with media to establish the levels of mercury lost to the piping and column internals.

- A pump will be installed with the discharge piped to each column. The inlet to the pump will be centered and the inlet screen positioned approximately 4 inches above the sediment to ensure that the water collected is representative. The pump will be capable of supplying approximately 2 gallons per minute at constant pressure.

- A single 1 micrometer particulate filter will be installed between the pump and the columns.

Sample points will be installed on the discharge of each of the columns and before and after the sediment pre-filter.

Flow meters/controllers will be installed on the inlet of each column in order to control flow.

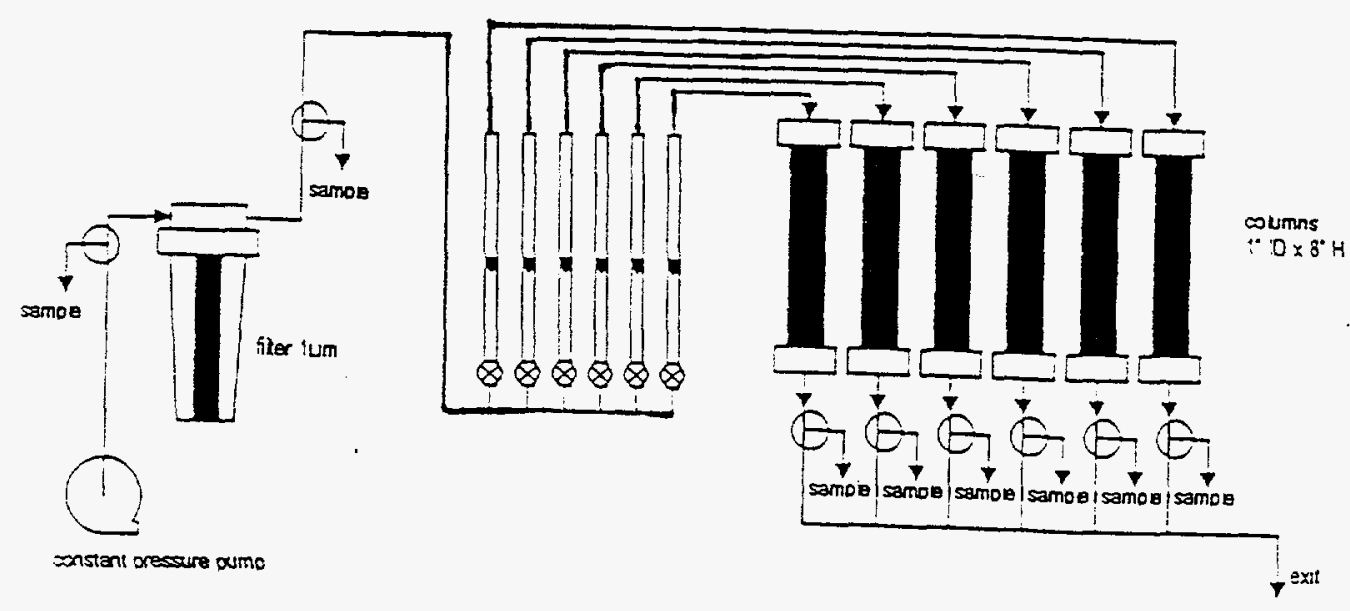

Figure 1. Schematic of sorption column equipment. 
The columns will be insulated and we will rely on the flow to prevent freezing in the pump and tubing. The apparatus will be drained whenever the pump is shut down.

\subsection{Lake Reality Inlet Equipment}

The equipment will be installed on the east side of the creek, just north of Second Avenue where the creek enters the lake through the corrugated pipes. The equipment will be rack mounted and temporarily installed. Power (110 volt ac) for the pump will be supplied from the light pole, (\#375) which is very close to the test location. Key features for the equipment will be as follows. A sketch of the equipment is shown in Figure 2.

- One filter housing will be installed. The housing will accept a cartridge that is approximately 4 inches in diameter and 10 inches in length and will be constructed of molded plastic resin. The filter housing will be run empty (without cartridge) initially to measure the quantities of mercury lost to the piping and filter housing internals.

- A pump will be installed in the creek and the discharge piped to each filter housing. The inlet to the pump will be centered in the creek with the inlet screen positioned approximately 4 inches above the sediment bed in the creek to ensure that the water being tested in representative of the creek.

- Sample points will be installed on the inlet and discharge of the filter housings.

- Flow meters/controllers will be installed on the inlet of the filter in order to control flow.

- There will be no freeze protection installed. We will rely on the flow to prevent freezing and the unit will be drained whenever the pump is shut off.

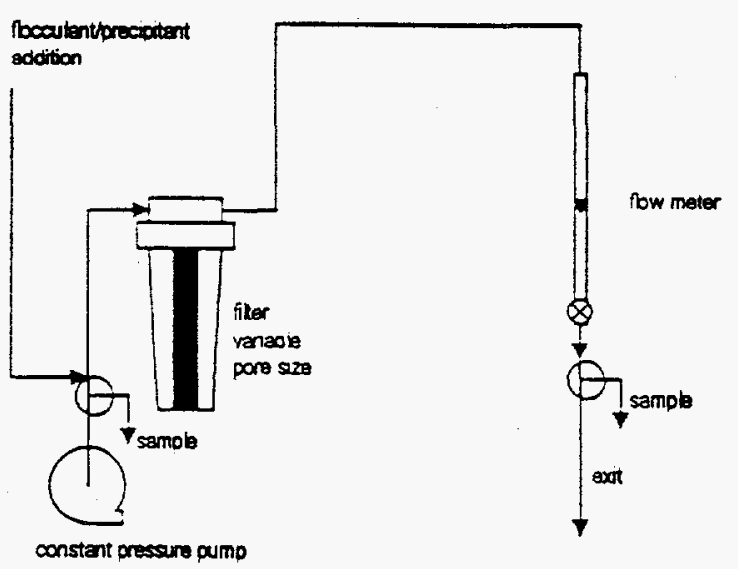

Figure 2. Schematic of filtration equipment. 
A flocculant/precipitant addition line will be installed for possible future testing.

\subsection{TEST PLAN}

The following is intended to be a general description of the test and sample plans, however, a more detailed Data Quality Objectives document will be prepared prior to initiation of the field work. Prior to the initiation of sorbent media or test filter, creek water will be pumped through the system to demonstrate leak-free operation and to ensure that the columns and piping are conditioned. Following an initial 24-hour run, samples will be taken at one of the monitoring points to determine the levels of mercury lost from the test water by adherence to the walls of the columns and tubes. These samples will be repeated following a second 24 -hour run. Data from these conditioning runs will be used to differentiate mercury losses to equipment and to media and filters.

The testing at the North/South Pipe and Lake Reality inlet will differ since sorbents will be tested at the North/South Pipe and filters will be used at Lake Reality inlet.

Sampling will be be nearly identical in both locations and as a result the following description of testing will apply to both locations. The tests will consist of approximately six runs for each of an estimated four sorbent candidates, the reference sorbent and the blank column for each series of tests. The first run for each sorbent candidate will be at approximately 0.1 bed volume per minute and will be continued for approximately 24-hours. The flow will be increased in four steps to a maximum flow with 24-hour runs at each step. The succeeding flow rates will be .3, 1.0, 3.0 and a minimum of 6.0 bed volumes per minute. A maximum flow of greater than 6.0 bed volumes per minute is desired, however, this upper level will be determined by equipment limitations. A sixth and final run will be made at the original flow rate of 1 bed volumes per minute. Sampling will be conducted at the following approximate intervals for each of the six flow levels. The runs will be initiated at approximately $12: 00$ noon each day.

First sample after approximately 20 -hours run time at that flow rate or about 8 AM.

Second sample at 24-hours run time at that flow rate or about 12:00 noon.

Following the 24-hour sample, the flow will be increased to the next level.

The normal mode of operation will be to suspend the testing during the weekends. As a result, the pump will be shut down and the equipment drained at noon on Fridays and the pump restarted about noon on Mondays. For the filter testing, the flow rates for each filter will be determined by the pressure drop. Also, an initial test will be conducted at the various flow rates without a cartridge in the filter housing to determine the mercury losses to the housing and piping. Although not a part of this current test plan, consideration will be given to testing the addition of a flocculant or precipitant 
upstream of the filter. The filter testing will be suspended during periods of significant rainfall.

At the end of each series of sorbent tests, the sorbent will be removed from the columns, packaged for possible future analysis and stored by Chem Tech at their facilities at ORNL. At the end of all testing or one year from the completion of the tests, the contaminated sorbent will be disposed of at ORNL using Chem Tech procedures.

\subsection{SAMPLING REQUIREMENTS}

The following describes in general terms the sampling and quality assurance objectives and requirements for the test program. The specific requirements outlined in the Sample Management Organization (SMO) guidance to the analytical laboratories and the Data Quality Objectives document (to be prepared prior to initiation of field work) may provide more detailed sampling and sample handling requirements and will take precedence over this document.

\subsection{Routine Sampling Requirements}

Analytical Method to Be Used

The mercury analyses will be obtained by using EPA Method 1631 .

\section{Sample Points}

Sample points are located at the discharge of each of six columns and before and after the sediment filter. Thus, each day there will be fourteen samples (two per flow level) and a blank sample collected for a total number of samples of 15 each day.

\section{Sample Times}

As outlined previously, there will be six runs, at increasing flow rates, for each of the sorbent/filter candidates. For each run, samples will be taken after 20 -hours stable running at that flow rate (approximately 8:00 AM) and then again after 24-hours run time (approximately 12:00 noon). Following the 24 -hour sample, the flow rates will be increased to the next level.

\section{Sample Bottles}

The sample bottles to be used shall be glass IChem bottles (125 or $250 \mathrm{~mL}$ ) with Teflon-lined closures or equivalent. These bottles can be obtained as stock items by Chem Tech via the LMES AVID ordering system. Care should be taken to not tighten the caps too tightly. 


\section{Filtration of Samples}

Experience has shown that effluents from some sorbents contain mercury in particulate form and thus further removal efficiency can be achieved if the final step is filtration. In previous related work, the filtration of the sample has raised questions relative to the mercury removal efficiency of the sorbent candidates. To provide more data on this issue, the majority of the samples will not be filtered, however, for each sorbent there will two filtered samples; taken at the 24-hour sample point for the maximum flow (run five) and the minimum flow (run six). Thus, there will be twelve (12) routine samples for each sorbent candidate. To minimize the influence of any sorbent particulate reaching the sample bottle, the sample point will be purged for five minutes before all unfiltered samples are taken.

\section{Preservation of Samples}

Based on previous related work with very low levels of mercury, to prevent contamination of the sample, the samples have not been preserved in the field, but in the analytical laboratory upon receipt. By requiring the laboratory to process (acidify) the samples directly in the sample bottle, any mercury lost to the walls is quantitatively recovered. The samples will be packed in blue ice upon collection and shipped to the laboratory via overnight carriers.

\section{Shipping Requirements}

Shipping of samples is highly controlled by DOT regulations. As a general rule, all samples must be HP surveyed and include a memo indicating that historical monitoring and process knowledge have indicated no rad above limits allowed by analytical lab.

\subsection{Quality Control Requirements Number of Blanks To Be Used}

Experience with related field samples for low levels of mercury has not demonstrated the value of numerous blank samples. Instead, as indicated in the Test Plan, an empty column will be operated in parallel with each set of sorbent candidates and the reference sorbent. Both the reference sorbent and blank columns will be sampled as the sorbent candidates are sampled. A "pure water" sample will be supplied to the analytical laboratory with each set of samples as a quality control check.

\section{Other QA Requirements}

The holding times for these type samples per EPA is 28 days but other factors will require much faster turn around time. Depending on the number of media candidates identified for testing and the available time for testing, one or more duplicate media runs will be made to validate the accuracy and repeatability of the test results. 


\subsection{HEALTH AND SAFETY REQUIREMENTS}

The Health and Safety requirements for the RMPE program is covered in Y/ER-219. A separate project specific Health and Safety Plan is being provided for this project. This project specific plan will be used for the readiness review prior to the initiation of field work.

\subsection{SCHEDULE}

Attachment A provides a detailed schedule for the overall project. Chem Tech is scheduled to install the field equipment in late December following the review of equipment sketches by the project team. The field work is scheduled to start during the week of January 12, 1998 (following a satisfactory readiness review) and continue for approximately 25 work days. Following the completion of the field work, a complete package of analytical results will be developed and submitted to AAMU for analysis and drafting of the final report. Following review of the draft report by the project team, AAMU will finalize the report by the end of March 1998.

\subsection{EQUIPMENT DECONTAMINATION AND DISMANTLEMENT}

Following completion of all field testing, the equipment will be cleaned, the equipment and piping checked for radioactivity via wipe testing and shipped back to ORNL. Cleaning fluids and materials will be disposed of at ORNL using the approved Chem Tech procedures. 


\section{APPENDIX A}

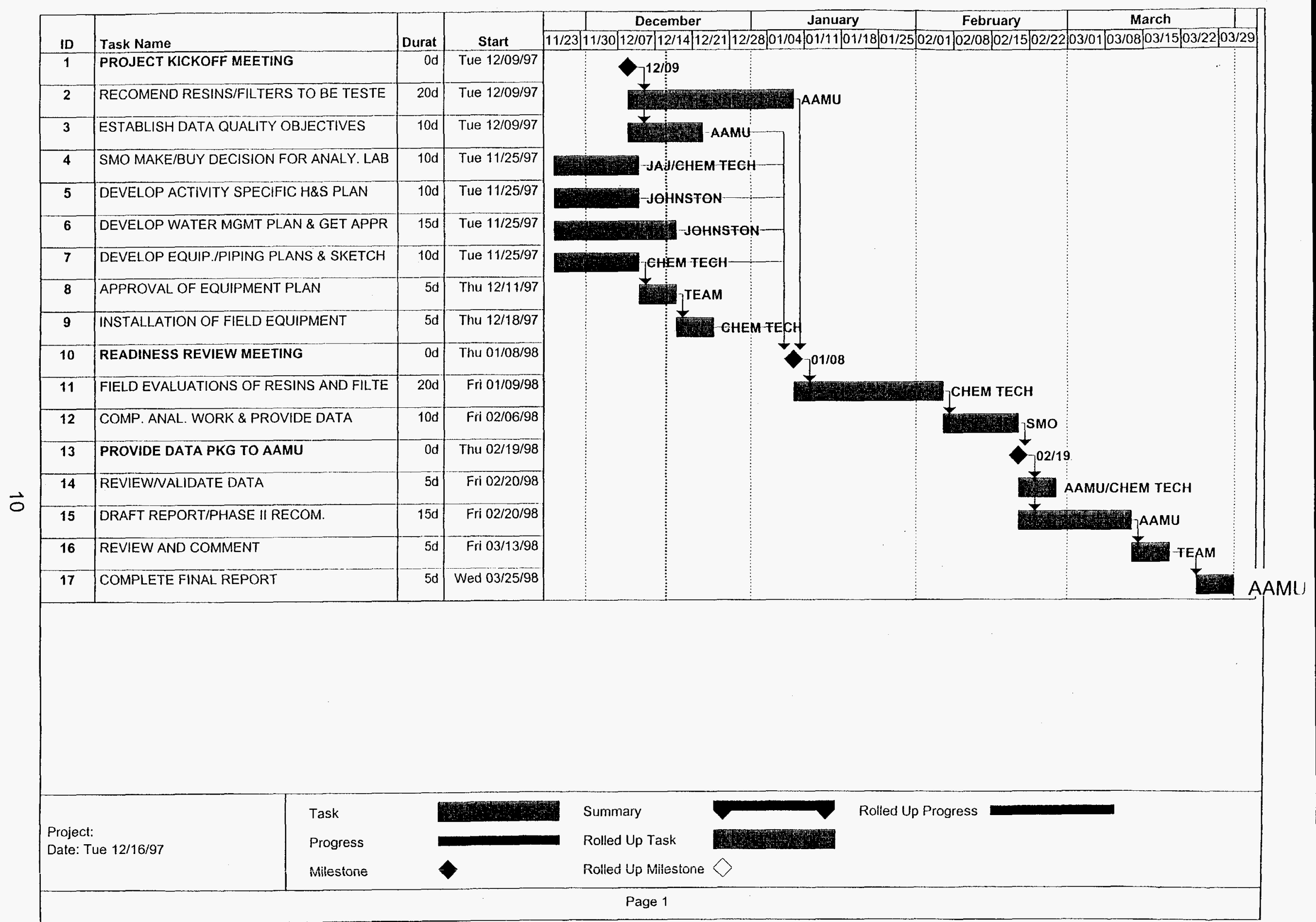




\section{DISTRIBUTION}

1. E. T. Collins

2. J. F. Hensley

3. P. T. Owen

4. L. B. Raulston

5. File-EMEF DMC-File 